\title{
Preparation of snail cyst and PEG-4000 composite carriers via PEGylation for oral delivery of insulin: An in vitro and in vivo evaluation
}

\author{
Mumuni A Momoh ${ }^{1 \star}$, Ossai C Emmanuel ${ }^{2}$, Azubuike C Onyeto ${ }^{3}$, Youngson \\ Darlington ${ }^{1}$, Franklin C Kenechukwu ${ }^{1}$, Kenneth C Ofokansi ${ }^{1}$, Anthony A \\ Attama ${ }^{1}$ \\ ${ }^{1}$ Drug Delivery Research Unit, Department of Pharmaceutics, Faculty of Pharmaceutical Sciences, ${ }^{2}$ Department of \\ Biochemistry, Faculty of Biological Sciences, ${ }^{3}$ Department of Pharmacology and Toxicology, Faculty of Pharmaceutical \\ Sciences University of Nigeria Nsukka, Nigeria
}

*For correspondence: Email: audu.momoh@unn.edu.ng; Tel: +234-8037784357

Sent for review: 18 September 2018

Revised accepted: 17 April 2019

\begin{abstract}
Purpose: To develop PEGylated mucin as a carrier system for oral insulin delivery.

Methods: Varied ratios of snail cyst were molecularly modified with polyethylene glycol 4000 (PEG 4000). Briefly, In each case, $20 \mathrm{~g}$ quantities of snail cyst and PEG 4000 were separately dispersed in distilled water, stirred and allowed to stand for $24 \mathrm{~h}$ to produce a homogeneous dispersion and clear solution, respectively. The solution of PEG was added to the snail cyst dispersion, stirred and allowed $12 \mathrm{~h}$ for molecular interaction. The mixture was added to a 250-mL beaker containing $100 \mathrm{~mL}$ of light liquid paraffin. The microparticles were obtained after stirring and removing the paraffin using chilled acetone. The obtained PEGylated mucin matrices, which were subsequently loaded with insulin using a diffusion method, characterized for particles size, drug loading, encapsulation efficiency, in vitro drug release and evaluated for oral application in diabetic rats.

Results: The polymer hybrids improved insulin encapsulation efficiency (max $82.3 \%$ ), gave. polydispersity indices that ranged from $0.11 \pm 0.1$ to $0.24 \pm 0.2$, zeta potential values between $28 \pm 0.3$ and $38 \pm 1.1 \mathrm{mV}$. Insulin release was highest ( $68 \%$ in $6 \mathrm{~h}$ ) for batch $\mathrm{C}$ and was sustained for $10 \mathrm{~h}$ in simulated intestinal fluid. The optimized batch (C-5) showed higher hypoglycaemic activity (56.5\%) than control $(0.5 \%)$ in diabetic rats.

Conclusion: The results suggest that PEGylated mucin can potentially be developed as a platform for oral insulin delivery.
\end{abstract}

Keywords: Snail-cyst, PEGylation, Diabetes, Microparticles, Archachatina marginata

\begin{abstract}
This is an Open Access article that uses a fund-ing model which does not charge readers or their institutions for access and distributed under the terms of the Creative Commons Attribution License (http://creativecommons.org/licenses/by/4.0) and the Budapest Open Access Initiative (http://www.budapestopenaccessinitiative.org/read), which permit unrestricted use, distribution, and reproduction in any medium, provided the original work is properly credited.

Tropical Journal of Pharmaceutical Research is indexed by Science Citation Index (SciSearch), Scopus, International Pharmaceutical Abstract, Chemical Abstracts, Embase, Index Copernicus, EBSCO, African Index Medicus, JournalSeek, Journal Citation Reports/Science Edition, Directory of Open Access Journals (DOAJ), African Journal Online, Bioline International, Open-J-Gate and Pharmacy Abstracts
\end{abstract}

\section{INTRODUCTION}

Excipients are generally considered as one of the cardinal factors in effective drug delivery [1]. It has been on the front burner in the field of scientific drug discovery and formulation to modify the existing carriers to enable their full utilisation as finding new excipients is very 
tasking and time consuming. The failure in the delivery of sensitive molecules like peptides and insulin for oral administration in the management of diabetes has been a serious issue among the health practitioners. This critical issue has been justified and recently received increased attention as to prepare a different entity with superior functions compared to the native or individual materials [2-4]. In this case, the modified excipients or their combinations are expected to have an improved drug delivery properties.

Polymeric nano/microparticles have been developed to facilitate clinically applicable oral delivery of sensitive drugs like insulin. Polyethylene glycol (PEG) is a non-toxic polymer that has been used in various pharmaceutical drug delivery systems because of its good biocompatibility and biodegradability [5].

Snail cyst (SC) is a natural substance that serves as protective covering of the opening of the snail shell during unfavourable condition. This cyst is said to contain some slimy features that aid in mucoadhesion. Previous reports have shown that the snail cyst possessed high mucous content and some minerals that are of health benefits [6].

In recent times, SC has gained attention in the area of drug delivery along with the mucin obtain from the mucous content of snail slime as a result of their mucoadhesive properties [6]. Insulin is a therapeutic macromolecule intensively used to improve the life of diabetics. To date, administration of insulin is by the subcutaneous route only and this is associated with unwanted side effects and poor compliance. In this study insulin-loaded snail cyst and PEG 4000 microparticles were prepared via molecular PEGylation method and characterized for in vitro release and in vivo hypoglycaemic activity.

\section{EXPERIMENTAL}

\section{Materials}

Polyethylene glycol 4000 (Germany), insulin (EliLily and Company Indianapolis, USA), sorbic acid, sorbitol (BDH, England), and polysorbate80 (Uniqema, Belgium). All other reagents were used as procured. Double distilled water (Lion Water, Nigeria) was used throughout the study.

\section{Preparation of snail cyst (SC)}

The SC was obtained from snail by gently removing it from the shell cover. The whitish flakes were cleaned off of any dirt and washed in distilled water. The snail cysts were dried and pulverised using an end-runner mill (Pascal Engineering Co. Ltd, England). The resultant powder was soaked in water for $24 \mathrm{~h}$ and the insoluble suspended particle was removed followed by lyophilization to obtain a smooth powder of SC.

\section{Preparation of PEGlyated snail cyst}

A $20 \mathrm{~g}$ quantity of snail cyst and PEG-4000 at ratios shown in Table 1 was dispersed in $100 \mathrm{~mL}$ beaker containing distilled water to produce a 20 $\% \mathrm{w} / \mathrm{v}$ homogeneous dispersion. The SC dispersion was added into $250 \mathrm{~mL}$ beaker containing $20 \mathrm{~mL}$ of soft liquid paraffin and thoroughly mixed using Silverson mixer (Adelpha 4R, England) at $2000 \mathrm{rpm} 10 \mathrm{~min}$. A $20 \mathrm{~mL}$ of the PEG-4000 solution was gradually added to the snail cyst dispersion with continue stirring under magnetic stirrer at a stirring speed of $350 \mathrm{rpm}$ for $20 \mathrm{~min}$. The dispersion was further homogenised using an Ultrasound sonicator (AT-500 Sonicator, India) at $60 \mathrm{~W}$ for $5 \mathrm{~min}$ in an ice bath. The microparticles formed was precipitated using chilled acetone, filtered using a filter paper (Whatman, No 1, USA), and washed off of liquid paraffin several times with a mixture of acetone and $n$-hexane (3:1). The final microparticles were recovered, air dried and lyophilised.

\section{Insulin loading}

A diffusion loading method was used to prepare insulin-loaded microparticles. Briefly, $5.0 \mathrm{~g}$ quantity of prepared microparticles was placed in a $10 \mathrm{~mL}$ clean glass plate and a $5.0 \mathrm{~mL}$ volume of the insulin solution $\mathrm{pH} \mathrm{7.3,} 100$ $\mathrm{IU} / \mathrm{mL}$ ) was gradually added to $5 \mathrm{~g}$ microparticles in a plate, which was gently shaken. Thereafter, the mixture was allowed to stand for $10 \mathrm{~min}$ to enable drug diffusion into the microparticles. The excess insulin solution was gently removed and the insulin-loaded microparticles were lyophilized. The recovered insulin-loaded microparticles was collected and used for further studies. The composition of insulin-loaded MPs is depicted in Table 1.

Table 1: Composition of Insu-MPs

\begin{tabular}{lccc}
\hline Batch & SC (g) & $\begin{array}{c}\text { PEG-4000 } \\
(\mathbf{g})\end{array}$ & $\begin{array}{c}\text { Insulin } \\
(\mathbf{m L})\end{array}$ \\
\hline C1 & 1.0 & 1.0 & 5.0 \\
C2 & 1.0 & 2.0 & 5.0 \\
C3 & 1.0 & 3.0 & 5.0 \\
C4 & 1.0 & 4.0 & 5.0 \\
C5 & 1.0 & 5.0 & 5.0 \\
\hline
\end{tabular}

$\mathrm{SC}=$ snail cyst, $\mathrm{PEG}=$ polyethylene glycol, Insu-MPs = insulin microparticles 


\section{Differential scanning calorimetry (DSC)}

The thermal property of insulin-loaded MPs was determined by differential scanning calorimetry (DSC) (Shimadzu DSC 204 F1, Japan). A 5.0 mg quantity each of the insulin-loaded MPs was weighed and placed on an aluminum pan, hermetically sealed, and the thermal behaviour determined over a temperature range of $20-220$ ${ }^{0} \mathrm{C}$ under a $10 \mathrm{ml} / \mathrm{min}$ nitrogen flux at a heating rate of $10{ }^{\circ} \mathrm{C} / \mathrm{min}$. The baselines were corrected using an empty pan, and all the thermograms were baseline corrected.

\section{Evaluation of surface morphology of insulin- loaded MPs}

The surface morphological characteristics of insulin-loaded MPs were evaluated using a scanning electron microscope (SEM-1000, Japan) following the standard procedure as stated in an earlier work [7]. The results were presented using a three-dimensional model.

\section{Determination of micromeritic properties}

A 10 gram quantity each of the batches of the preparations was weighed and used to evaluate the tapped and bulk density of the microparticles. The angle of repose (AR) and Carr's index (Cl) were also evaluated using standard methods [7]. Briefly, a rubber funnel was properly clamped on the retort stand. In each case, microparticle samples with known weight were gradually placed into the funnel with the orifice of the funnel closed. Upon opening the orifice, the entire microparticles were allowed to flow freely through the orifice on plain sheet of paper. Thereafter, the height and radius of the microparticle was measured using a meter rule. The angle of repose $(\theta)$ and Carr's compressibility index $(\mathrm{Cl})$ were calculated using Eqs 1 and 2, respectively.

$\theta=\tan ^{-1}\left(\frac{M P}{R M P}\right)$

where HP and RHP are height of powder and radius of heap of powder respectively.

$\mathrm{CI}(\omega)=\frac{\ell_{\mathrm{T}}-\ell_{\mathrm{B}}}{f_{\mathrm{T}}} \times 100$

where $\ell_{\mathrm{T}}$ and $\ell_{\mathrm{B}}$ are tapped and bulk density respectively.

\section{Determination of particle size, polydispersity index and zeta potential}

The particle size, polydispersity index (PDI) and zeta potential (ZP) of the insulin-loaded MPs were determined using a dynamic light scattering
(Malvern Zetasizer Nano, Japan). In each case, samples were diluted with distilled water and measured at an angle of $173^{\circ}$ and temperature of $25{ }^{\circ} \mathrm{C}$. All measurements were performed in triplicates.

\section{Assessment of encapsulation efficiency (EE) and drug loading (DL)}

The EE (\%) and DL of insulin-loaded MPs were studied following an earlier method. Briefly, 50 $\mathrm{mg}$ of the insulin-loaded MPs was placed inside a pre-treated polycarbonate dialysis membrane bag of $20 \mathrm{kDa}$, molecular weight cut off of 8000 (MWCO 8000) containing $20 \mathrm{~mL}$ of deionized water and centrifuged (Kubotal model RL-1700, Japan), at $11,000 \mathrm{rpm}$ for $30 \mathrm{~min}$ at $10^{\circ} \mathrm{C}$ The amount of free insulin in the supernatant was measured using a UV spectrophotometer at 271 nm (Jenway 65042, Germany). The concentration of free insulin in the supernatant was calculated from a standard curve of insulin. EE (\%) and DL were calculated using Eqs 3 and 4 , respectively.

$E E=\frac{M I A-M I S}{M Y A} \times 100 \ldots \ldots \ldots$ (3)

where MIA =mass of insulin added, MIS=mass of insulin in suspension

$D L=\frac{M A-M T S}{T M M} \times 100$

where MIA = mass of insulin added, MIS = mass of insulin in suspension, TMM = total mass of microparticles

\section{In vitro release studies}

In vitro release of insulin was evaluated in two different buffer solutions according to an earlier work with slight modification [8]. In brief, phosphate buffered saline (PBS, pH 7.2) was prepared to simulate the gastrointestinal tract (GIT) environment. Approximately $30 \mathrm{mg}$ of the prepared insulin-loaded microparticles was placed in a polycarbonate dialysis membrane and a $2.0 \mathrm{~mL}$ volume of the dissolution medium was added. The membrane was properly secured at both ends by tying it with thread to prevent leakage. The prepared dialysis membrane was suspended in $200 \mathrm{~mL}$ of PBS and at different time intervals, $2 \mathrm{~mL}$ aliquot was withdrawn and replaced with same solution. The withdrawn samples were filtered, appropriately diluted and analysed using high pressure liquid chromatography (HPLC) as previously described [9]. The concentration of insulin released in the medium was calculated and plotted against time. All the experiments were performed in triplicate. 


\section{In vivo diabetic study}

Wistar albino rats weighing 180 were obtained and were allowed to acclimatize to the new experimental environmental condition. The entire animals were weighed and they had access to food and water before the study. Prior to the induction of diabetes, they were fasted overnight and the baseline glucose level was determined with a glucometer (Accu-check Roche, USA). The rats were made diabetic using alloxan monohydrate solution as previously reported [10]. Rats with blood glucose level above 220 $\mathrm{ml} / \mathrm{dl}$ were considered diabetic and were enrolled in this investigation.

\section{Oral administration of insulin-MPs}

Four groups of seven rats per group were used in this investigation. Rats in group I received saline, those in groups II and III received insulin solution orally and subcutaneously (s.c), respectively. Rats in group IV received Insu-MPs (C-5) equivalent to $40 \mathrm{I} . \mathrm{U} / \mathrm{kg}$ with the aid of an intragastric tube. Blood samples were collected from the tail of the rats and the blood glucose concentration was obtained as a percentage of the baseline using the glucometer (Accu-Check, Roche, USA). All the animal experiments in this study was approved by the institutional (University of Nigeria) Review Board for Use of Animal Subjects under the Directorate of Research (no. DOR/UNN/17/00014) and were in compliance with the Federation of European Laboratory Animal Science Association and the European Community Council Directive (Publication No (86/609/EEC) of November 24, 1986 (11).

\section{Statistical analysis}

All experimental data were expressed as (mean \pm standard error (SE, $n=3$ ). Statistically significant differences were evaluated using oneway analysis of variance (ANOVA) or a two-tailed t-test using SPSS Version 11 (SPSS Inc, Chicago, IL, USA). Differences were considered significant at $p<0.05$

\section{RESULTS}

\section{Micromeritics and recovery rate of the microparticles}

Table 2 depicts the results of micromeritics properties and the recovery rate of the microparticles. The recovery rate was very high, the maximum and minimum recovery rate were 88.0 and $76.2 \%$ for batch C3 and C1 respectively. However, there was no significant difference $(p<0.05)$ among the batches of the preparation. Hence, none of the formulations showed up to $100 \%$ recovery rate, due to losses that occurred during the processes of scrapping, pulverising and harvesting the microparticles.

\section{Particle size, zeta potential and polydispersity index of the microparticles}

Table 3 shows the particle properties of the formulations. The particles sizes and the zeta potential of the preparation range from 261.3 $321.5 \mu \mathrm{m}$ and $28-38 \mathrm{mV}$, respectively. The polydispersity indices range from $0.11 \pm 0.1$ to $0.24 \pm 0.2$.

\section{Encapsulation efficiency and loading capacity}

The encapsulation efficiency (EE) and loading capacity (DC) as shown in Table 3, ranged from $61.0-82.3 \%$ and $23.2-42.6 \%$, respectively. EE and DC increased as the concentration of the PEG-4000 increased. However, there was no significant difference among the batches of the formulation.

Table 2: Micromeritic properties and recovery rate of insulin-loaded microparticles

\begin{tabular}{lccccc}
\hline Batch & $\begin{array}{c}\text { BD } \\
\left(\mathbf{g} / \mathbf{c m}^{3}\right)\end{array}$ & $\begin{array}{c}\text { TD } \\
\left(\mathbf{g} / \mathbf{c m}^{3}\right)\end{array}$ & $\begin{array}{c}\text { Cl } \\
(\%)\end{array}$ & $\begin{array}{c}\text { AR } \\
(\mathbf{(})\end{array}$ & $\begin{array}{c}\text { RR } \\
(\%)\end{array}$ \\
\hline C1 & 0.351 & 0.481 & 12.12 & 28.40 & 76.21 \\
C2 & 0.341 & 0.491 & 19.17 & 29.21 & 81.17 \\
C3 & 0.361 & 0.487 & 26.11 & 26.41 & 88.03 \\
C4 & 0.411 & 0.512 & 18.91 & 30.11 & 81.27 \\
C5 & 0.431 & 0.514 & 24.11 & 29.16 & 89.25 \\
\hline
\end{tabular}

Table 3: Mean size, zeta-potential (ZP), polydispersity index (PDI), drug-loading (DL) and encapsulation efficiency (EE \%) of insulin-loaded microparticles ( $n=$ 5)

\begin{tabular}{llllll}
\hline Batch & $\begin{array}{l}\text { PS } \\
(\boldsymbol{\mu m})\end{array}$ & $\begin{array}{l}\text { ZP } \\
(\mathbf{m V})\end{array}$ & PDI & $\begin{array}{l}\text { DL } \\
(\%)\end{array}$ & $\begin{array}{l}\text { EE } \\
(\%)\end{array}$ \\
\hline C1 & 261.3 & $32 \pm$ & $0.12 \pm$ & 23.2 & 61.0 \\
& \pm 1.3 & 0.2 & 1.1 & & \\
C2 & 268.4 & $28 \pm$ & $0.16 \pm$ & 30.0 & 70.8 \\
& \pm 4.0 & 0.3 & 0.7 & & \\
C3 & 277.2 & $29 \pm$ & $0.22 \pm$ & 34.1 & 70.9 \\
& \pm 2.3 & 1.0 & 1.4 & & \\
C4 & 311.3 & $33 \pm$ & $0.11 \pm$ & 34.4 & 74.2 \\
& \pm 0.1 & 0.9 & 0.1 & & \\
C5 & 321.0 & $38 \pm$ & $0.24 \pm$ & 42.6 & 82.3 \\
& \pm 0.3 & 1.1 & 0.2 & & \\
\hline
\end{tabular}

\section{Thermal properties}

The thermal properties of the prepared microparticles are shown in Figure 1. The thermograms of the insulin-loaded MPs were intense endothermic peaks that ranged from 95.0 
- $95.5{ }^{\circ} \mathrm{C}$ in all the formulation. This clearly shows no much difference among the insulin microparticles prepared.

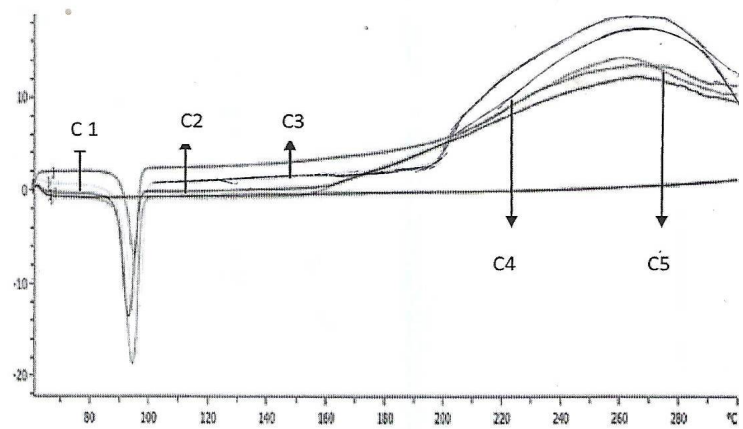

Figure 1: DSC thermograms for insulin-MPs batches (C1, C2, C3, C4 and C5)

\section{Morphological features of the microparticles}
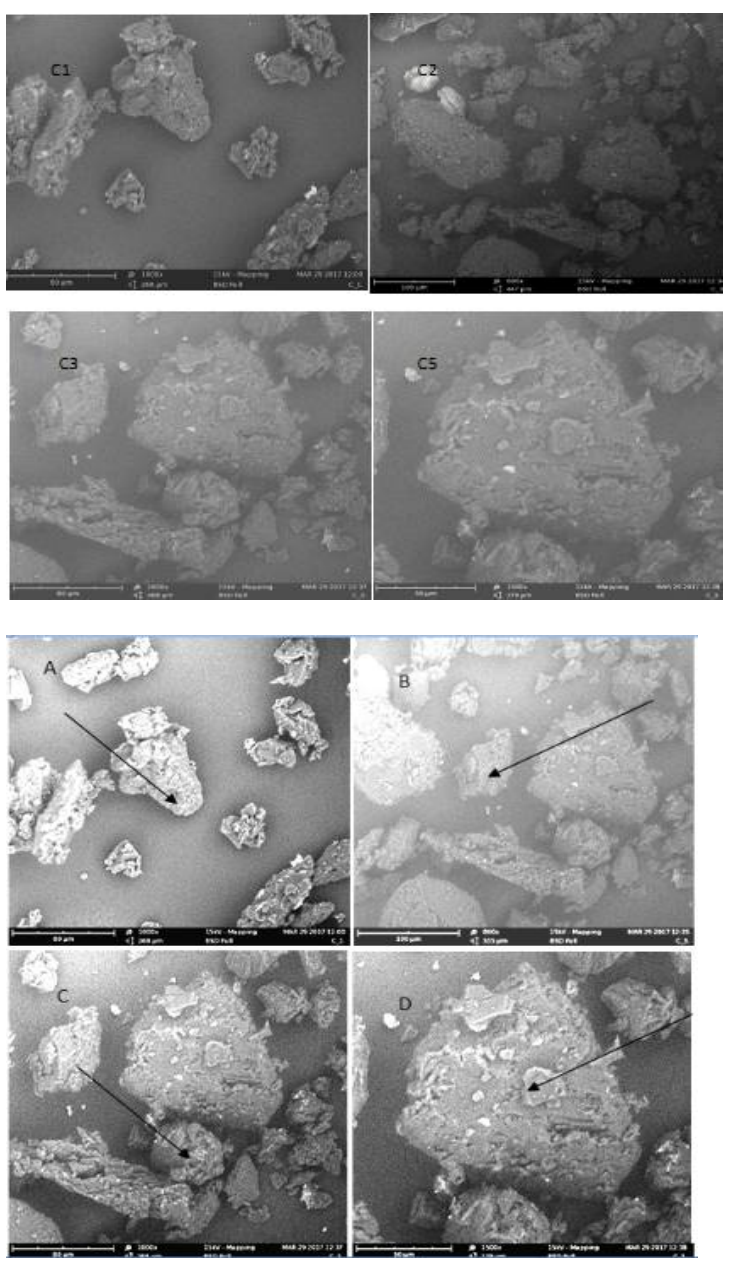

Figure 2: A representative photomicrographs of the morphology of insulin-MPs $(A 1=C 1, B=C 2, C=C 3$ and $D=C 5$. $C 4$ is very similar to that of $C 5$. The arrows indicate the particle shape of the various MPs

The morphologies of all the batches of the formulations were evaluated by using SEM and the micrographs thus obtained are depicted in
Figure 2, which shows irregularly-shaped and free-flowing particles, with increasing size in the order of $\mathrm{C} 1<\mathrm{C} 2<\mathrm{C} 3<\mathrm{C} 4<\mathrm{C} 5$.

\section{In vitro drug release from microparticles}

In vitro release of insulin in phosphate buffer of $\mathrm{pH} 7.2$ from the various batches of the microparticles prepared with snail cyst is graphically represented in Figure 3 . All the batches of the formulation showed sustained release characteristics over a period of $10 \mathrm{~h}$. Interestingly, there was an initial burst release of the insulin from the microparticles, which was more pronounced in the batch with high concentration of PEG to snail cyst (5:1). This was followed by more sustained drug release. Microparticles prepared with high content of PEG to mucin ratio (batch $\mathrm{C}-5$ ) had the tendency to fully sustain the release of insulin for prolonged period of time.

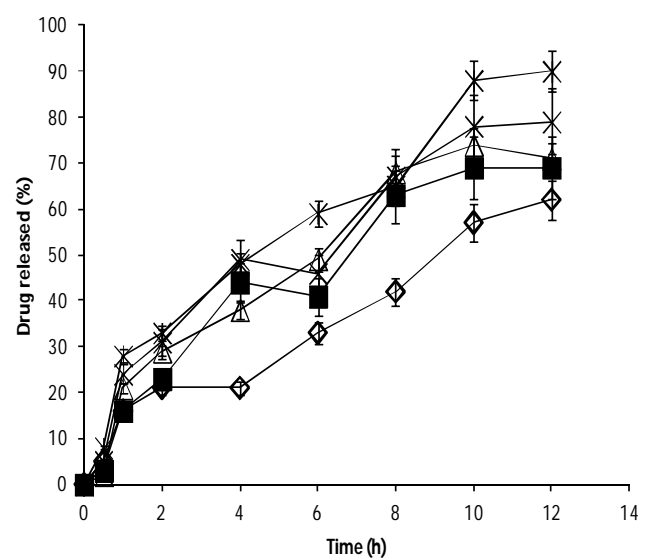

Figure 3: Insulin release profiles from microparticles in phosphate buffer $\mathrm{pH} 7.2$ from PEGylated-snail cyst

\section{In vivo anti-diabetic activity}

In vivo hypoglycaemic properties of the optimized batch (C-5) and the reference samples were investigated using alloxan-induced diabetic rat model and the results are presented in Figure 4. Results showed that there was no significant hypoglycaemic effect after oral administration of saline solution. On the contrary, rats dosed with subcutaneous injection of insulin showed a sharp and remarkable blood glucose level reduction. The onset of the pharmacological effect was very fast and attained a maximum effect at $4 \mathrm{~h}$ with nadir effect or decrease of $61 \%$ from the initial $100 \%$. After the period of $5 \mathrm{~h}$, the glucose level began to rise again and at $10 \mathrm{~h}$, it reached $88 \%$; nearly getting to the starting point of $100 \%$. In contrast, insulin solution administered orally, showed no significant blood glucose reduction when compared to the insulin-sc. Interestingly, oral administration $(40 \mathrm{IU} / \mathrm{kg})$ of the insulin- 
loaded MPs exhibited delayed onset of activity, but had prolonged hypoglycemic activity when compared to the insulin-sc administration (Figure 4). For insulin-loaded MPs, the hypoglycemic effect was maximum at $10 \mathrm{~h}$ with nadir effect of $54 \%$, and this activity was sustained for a longer period of time $(>10 \mathrm{~h})$.

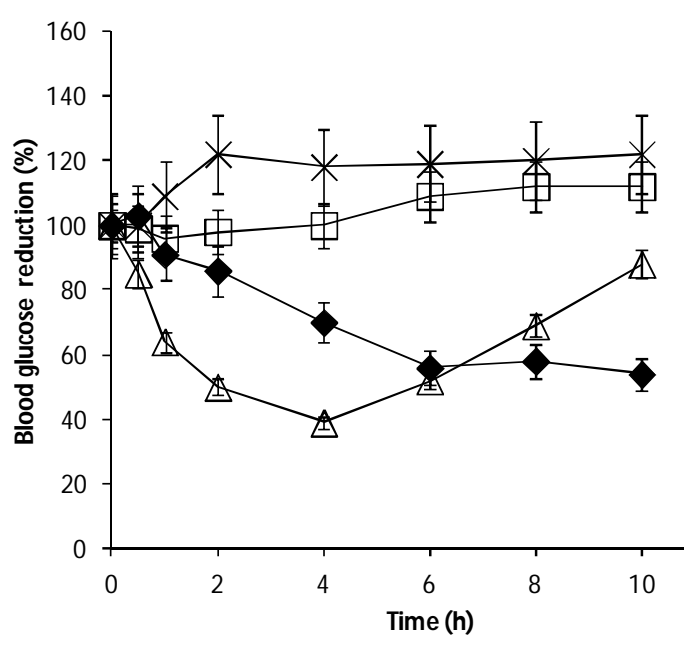

Figure 4: Effect on blood glucose levels in diabetics animal model after orally administered of insulinloaded microparticles (batch C-5), insulin solution (inssol), insulin subcutaneous (Ins-sc) and saline

\section{DISCUSSION}

The results of micromeritics properties and the recovery rate showed that the formulation method adopted in this study was good. The size of the particles is very important in the drug carrier, as it forms one of the key determinants of the amount of drug loaded in the formulations which directly affects the release and the pharmacokinetic activities of the drug. More so, the zeta potential is an important parameter of the microparticles, since the surface charge gives an indication of the electrostatic stability of the preparation and the degree in which the particles' will interact with the biological media [10]. From the study, the polydispersity indices indicate a unimodal size distribution of the formulations. Additionally, the majority of the particle sizes are within the lower micrometer range and their zeta potentials indicate that the formulations are stable.

The EE and DC of the formulations clearly showed that PEG-4000 had direct influence on the amount of drug incorporated into the polymer. In all cases, the EE and DC of the preparations were very high, which further proved that the formulation method was reliable and could be exploited further for possible future commercial preparations.
The thermal properties of the formulations indicate that the polymers are well blended resulting in a new polymer entity with a narrow PDI.

Morphological results indicate that there was no homogeneity in the morphology of the particles. It is worthy of note that increase in the amount of PEG-4000 created a significant increase in the size of the particles. The batches with lower concentration of PEG exhibited smaller particle size than batches with higher PEG-4000 concentration.

Results of in vitro drug release showed that insulin release from the microparticles prepared using the remote loading process as used in this work presented with the challenge of initial burst effect. This is because there is every tendency for part of the drug to adhere to the surface of the microparticles. In such cases, the interaction of microparticles with the dissolution medium will cause an early release of the peripheral drug on the outer surfaces of the microparticles resulting in an initial burst effect. Importantly, burst release resulting in biphasic release pattern may be utilized in therapeutic design of dosage forms especially in the management of disease condition like diabetes.

Previous studies had shown that this burst effect also occurred even in microparticles prepared using other established polymers such as polylactic acid and its analogues [12]. Additionally, peripheral attachment of the drug may occur as a result of expulsion during microparticles drying or drug migration as a result of solvent drags during drying. In this study, initial burst effect may be an advantage because it would lead to a high initial blood concentration of the drug (loading dose) and a gradual release of the remaining drug (maintenance dose).

Clinically, the objective of diabetes management is always to lower the blood sugar level and maintain it at a particular level that is not harmful. This is possible if a loading dose of the antidiabetics is administered, but this must not be confused with dose dumping. The subsequent slow release as seen in this formulation (Figure 4) would serve as the maintenance dose, which would further sustain the availability of the insulin in the plasma for a long period of time. It is worthy of note that none of the formulations emptied the entire drug in the form of dose dumping just after about $1 \mathrm{~h}$.

Results of anti-diabetic study showed that there was no significant hypoglycaemic effect 
observed after oral administration of saline solution because it did not contain any antidiabetic agent; rather it served as the negative control. However, subcutaneously administered insulin which served as positive control exhibited significant hypoglycemic effect. The rebound effect of rise in blood glucose observed in the study could be attributed to the relatively short circulating plasma half- life of the drug and the possibility of rapid clearance of the administered insulin from the system by the kidneys [13,14]. In contrast, insulin solution administered orally showed no significant blood glucose reduction when compared to the insulin-sc. This clearly indicates that oral insulin solution could not exert any meaningful hypoglycaemic effect and the reasons are attributed to; (i) intestinal enzymatic degradation of the peptides due to molecular cleavage sites when crossing the intestinal mucosa via active transport or passive diffusion, (ii) the high molecular weight of insulin hindering absorption into biological system and (iii) acidic environment of the gastrointestinal tract (GIT) affecting the stability of the insulin causing it to lose its biological activity.

Although the oral dose administered was higher than the dose for subcutaneous injection of insulin in diabetes treatment, this is due to lower absorption of oral route of drug administration. Pharmacologically, the onset of action for orally administered insulin was slow compare to the subcutaneously administered insulin, and this can be explained as follows: the preparation underwent a gradual swelling by the polymers and subsequently released the insulin from the microparticles via diffusion mechanism.

Moreover, the lag or delay onset time could also be attributed to the time for the microparticles to reach the site where the released insulin could be absorbed [13]. The prolonged effect was attributed to the snail cyst (as the carrier) and its combination with PEG in the form of PEGylation or complexation. The mucoadhesive property of the snail cyst allowed a closer intimacy of contact between the drug and mucosal wall of the GIT at the absorption area, and increased the residence time of the drug, and thus enhanced the permeability of the encapsulated drug.

Previous studies have shown that the polyethylene glycol chains have the ability to increase the apparent molecular size of peptide drugs and alleviate their high hydrophilicity thereby increasing their bioavailability and enhancing their cell membrane permeation $[13,14]$. Additionally, it has been established that polyethylene glycol has the capability to limit the globular filtration of the absorbed insulin in the system thereby prolonging the plasma circulation time $[15,16]$. This assertion was in agreement with previously reported PEG inclusion strategies to prevent the early clearance of the peptide from the system $[17,18]$.

The results of the hypoglycaemic activity in this study has further lent credence to the fact that steric hindrance of PEG network would prevent the early clearance of insulin and that its interaction with the mucus of the GIT played a synergistic role in protecting the environmental degradation of insulin thereby increasing its biological activity.

\section{CONCLUSION}

Insulin-loaded MPs for oral delivery have been successfully prepared with snail cyst and PEG4000 and evaluated for better diabetes management. The results showed the effectiveness of PEGylated mucin microparticles as a carrier system for oral insulin delivery as it was comparable to subcutaneously administered insulin after $6 \mathrm{~h}$. The findings also indicate that insulin-loaded PEGylated microparticles protect insulin from degradation in the GIT, facilitate its delivery in biologically active form, prolong its action and enhance its oral absorption in a diabetic animal model. Further studies will seek to evaluate the efficacy of the formulation in higher animals, with a view to surmounting the challenge of oral delivery of insulin.

\section{DECLARATIONS}

\section{Acknowledgements}

This work is sponsored by Tertiary Education Trust Fund (TETfund, grant number TETFUND/ DESS/NRF/STI/13/VOL.1). We thank Muhammad Usman (UDUS, Sokoto) and Jamiu Nurudeen (UNN) for their unconditional support during the animal study of this work.

\section{Conflict of interest}

The authors have no conflict of interest regarding this research paper. The research was financed by TETfund-NRF, Government of Nigeria.

\section{Contribution of Authors}

The work was original designed by Mumuni $A$ Momoh, Franklin C. Kenchukwu, Kenneth A. Ofokansi and Anthony A. Attama, and the studies were carried out by same people. Ossai C. Emmanuel, Azubuike C. Onyeto and Youngson Darlington; were involved in the in vivo / in vitro evaluations. The writing of the manuscript was 
done by the first four authors. All authors read the manuscript before it was submitted for publication..

\section{Open Access}

This is an Open Access article that uses a funding model which does not charge readers or their institutions for access and distributed under the terms of the Creative Commons Attribution License (http://creativecommons.org/licenses/by/ 4.0) and the Budapest Open Access Initiative (http://www.budapestopenaccessinitiative.org/rea d), which permit unrestricted use, distribution, and reproduction in any medium, provided the original work is properly credited.

\section{REFERENCES}

1. Rowe RC, Shesky PJ, Weoller PJ. Hand Book of Pharmaceutical Excipients, fourth ed., Pharm. Press, London, UK, 2003; pp 120-122, 544-545.

2. Cohen S, Lobel E, Trevgoda A, Peled YA. A novel in situ forming ophthalmic drug delivery system from alginates undergoing gelation in the eye, J Control Rel 1997; 44: 201-208.

3. Rebuma F, Tobias AO, Heidrun M. Identification of multiple cellular uptake pathways of polystyrene nanoparticles and factors affecting the uptake: relevance for drug delivery systems, Eur J Cell Biol 2014; 93: 323-337.

4. Jong Ah, Kim CA, Anna S, Kenneth A. Dawson, Role of cell cycle on the cellular uptake and dilution of nanoparticles in a cell population, Nat Nanotechnol 2012; 7: 6268.

5. Adikwu MU, Aneke KO, Builders PF. Biophysical properties of mucin and its use as a mucoadhesive agent in drug delivery: current development and future concepts, Nig. J. Pharm. Res 2005; 4: 60-69.

6. Builders PF, Kunle OO, Adikwu MU. Preparation and characterization of mucinated agarose: a mucin-agarose physical crosslink, Int J Pharm 2008; 356: 174-180.

7. Depeng L, Guohua JW, Yu LL, Zaizai T, Xiangdong K, Juming $Y$. Oral delivery of insulin using $\mathrm{CaCO}$-based composite nanocarriers with hyaluronic acid coatings, Mater Lett 2017; 188: 263-266.

8. Berchane NS, Carson KH, Rice-Ficht AC, Andrews MJ. Effect of mean diameter and polydispersity of PLG microspheres on drug release: Experiment and theory, Int J Pharm 2007; 22: 123-129.

9. Franklin CK, Anthony AA, Emmanuel Cl, Petra ON et al. Surface-modified mucoadhesive microgels as a controlled release system for miconazole nitrate to improve localized treatment of vulvovaginalcandidiasis. Eur J of Pharm Sci 2018; 111: 358-375

10. Raffaele F, Monica L, Claudio C, Massimo M, Maurizio D, Davide M. Investigation of size, surface charge, PEGylation degree and concentration on the cellular uptake of polymer nanoparticles, Colloid. Surface. B 2014; 123: 639-647.

11. European Community Council Directive on the ethics of experiments involving laboratory animals (Publication No: 86/609/EEC), November 24, 1986.

12. Jinsong L, Lihua $X$, Chuantong L, Dafeng Z, Siqian $W$, Zhennan $D$, Weiwei $L$, Haihong $X$, Qing $B$, Jianfeng $M$. Preparation and characterization of cationic curcumin nanoparticles for improvement of cellular uptake, Carbohydr Polym 2012; 90: 16-22.

13. Barthelmes J, Perera G, Hombach J, Dünnhaupt S, Bernkop-Schnürch A. Development of a mucoadhesive nanoparticulate drug delivery system for a targeted drug release in the bladder, Int J Pharm 2011; 416: 339-345.

14. Fei Y, Yang L, Chang Sheng L, Qin C, Gui HW, Wei G, Xue E. W, Dong HL, Winston DW, Xiao DC. Entericcoated capsules filled with mono-disperse microparticles containing PLGA-lipid-PEG nanoparticles for oral delivery of insulin, Int J Pharm 2015; 484: 181-191.

15. $L i$ LB, Tan YB. Preparation and properties of mixed micelles made of pluronic polymer and PEG-PE, J. Colloid Interface Sci 2008; 317: 326-331.

16. Zabaleta V, Campanero MA, Irache JM, An HPLC with evaporative light scattering detection method for the quantification of PEGs and Gantrez in PEGylated nanoparticles, J Pharm Biomed 2007: 44: 1072-1078.

17. Jiang $X$, Dai $H$, Leong KW, Goh GS, Mao HQ, Yang YY. Chitosan-g-PEG/DNA complexes deliver gene to the rat liver via intrabiliary and intraportal infusions, J Gene Med 2006; 8: 477-487.

18. Gao JQ, Eto Y, Yoshioka Y, Sekiguchi F, Kurachi S, Morishige T, Yao XL et al. Effective tumor targeted gene transfer using PEGylated adenovirus vector via systemic administration, J Control Release 2007; 122 : 102-110.

19. Biswal S, Sahoo J, Murthy PN. Characterisation of Gliclazide-PEG 8000 Solid Dispersions. Trop J Pharm Res 2009; 8(5): 417-424 